\title{
When Personal Becomes Political: M. Jenea Sanchez Documenting Migration from Mexico
}

\begin{abstract}
Even though "migration, immigration, and relocation is normative human behavior" (Blommaert and Verschueren in Byczkiewicz 5), migration across the U.S.-Mexico border has always been a controversial issue, raising incessant debates that have become even more acrimonious in the aftermath of the recent political debate on the immigration in the U.S. Owing to that, the stories of Latinx in the U.S. that should be read through both indigenous and immigrant paradigms have been reinterpreted through the latter one solely. The resulting borderlands tales illustrate "similar sentiments of nationalism, racism and nativism" (Byczkiewicz 5), while attempting at the more complex depiction of this conflicted and striated space. The purpose of this article is to analyze border stories depicted in Historias en la Camioneta and examine how M. Jenea Sanchez documents the journeys of those who want to get al otro lado, combining personal accounts and documentary footage, thus contributing to the ongoing discussion on the U.S.-Mexico border and borderlands.
\end{abstract}

Keywords: U.S.-Mexico border, borderlands, migration, documentary film, M. Jenea Sanchez

The organizers of the 2019 conference on migration, Flickering Landscapes - The Image of Migration: Landscapes and People, provide a broad definition of migration that "encompasses any movement of peoples, including migration within nations or across national boundaries" (flickeringlandscapes.com) and involving "the variety of the spaces migrants move across... land, and sea, and the built environment" (flickeringlandscapes.com). Their purpose is to further the ideas of omnipresence and naturalness of those movements that have been systematically and systemically challenged and questioned, particularly in recent years in the aftermath of subsequent "migrant crises" all over the world. These ideas are also reinforced by Viktoria Byczkiewicz who does research on the immigration in the U.S.-Mexico borderlands cinema. Quoting Blommaert and Verschueren, Byczkiewicz argues that "migration, immigration, and relocation is normative human behavior" (5); nevertheless "[b]orderlands tales the world round echo similar sentiments of nationalism, racism, and nativism" (Wodak in Byczkiewicz 5). This statement is particularly valid with regards to migration across the Mexican-American border that has always been a controversial issue, raising incessant debates, which have become even more acrimonious in the aftermath of the recent political debate on the immigration in the U.S. and the construction of the border wall. Consequently, the U.S.-Mexican border has appeared in numerous mainstream films and TV series. Those representations of the border and the issues related to Mexican-American borderlands not infrequently deploy sensational tone and perpetuate stereotypes in order to draw larger audiences. As a result, they do not leverage the power of the medium which, as Chris Lippard argues, "[i]n the face of increasingly dangerous paths of migration in today's transnational world" (www.flickeringlandscapes.com) is extremely important, as in such circumstances "the film has frequently been seen as having the potential to break 
down borders, eliciting sympathy and understanding for migrants - an extension of traditional views of the humanizing capacities and functions of the Arts and Humanities more generally" (flickeringlandscapes.com). The resulting one-sidedness of the aforementioned productions has been countered by documentaries attempting at a more complex depiction of the question of migration and the conflicted and striated space of the U.S.-Mexico border. The purpose of this article is to analyze border stories of migration represented in the short documentary Historias en la Camioneta (2010), and examine how its director M. Jenea Sanchez documents the journeys of those who want to get al otro lado, combining personal accounts and documentary footage and thus contributing to the ongoing discussion on the U.S.-Mexico border and borderlands.

M. Jenea Sanchez is an artist living between the two sides of the MexicanAmerican border, "born and raised in Douglas, AZ / Agua Prieta, SON" (mjeneasanchez. com). In the artist's statement she acknowledges the importance of her nepantlism, her life in-between the two states, her sense of unbelonging and negotiations between the two sides of the border. She also reveals how the situation on the U.S.-Mexico border influences her creative process. M. Jenea Sanchez admits:

My artistic endeavors reside in this threshold of liminality. My work has an inherent attribute of perceiving the world from a threshold, a physiological and psychological response to the mutation of cultural ideologies, engendered by my lifetime's interaction with the US Mexico border. As our society is aware of the political negotiations occurring on both sides of the US Mexico border fence, it is my interest to further expose the beauty of duality experienced by border citizens. (mjeneasanchez.com)

She continues her statement with the explanation about her approach to nomadic identities and the conflicted space of the borderlands:

As an artist, I strive to utilize this nomadic sensibility, by inserting myself between, among, and outside of the status quo of American and Mexican culture. As the sociopolitical climate of the border region remains controversial, I continue the conversation of permeability and how the perception of the actual line of the border can be reimagined. It is important to address that I believe borders are essential; borders in nature and the physical body (skin, blood), exemplify the importance of the marginalized bodies, as well as the importance of reciprocity between two entities. Barriers are what drive my artwork to respond to the dangers they implicate, for the peoples and environments involved, and bring forward the natural ways in which borders do and most importantly, could exist. (mjeneasanchez.com)

The artist's involvement with border-related issues is reflected consistently in her artwork of "drawing, video, installation, performance and photography" (mjeneasanchez.com), including Border Boneyard (2010), Tapiz de la Virgen de Guadalupe (2009/2011), or a series of border tapestry. In 2016 the artist also contributed to Borrando la Frontera/ Erasing the Border community project, coordinating the painting of the U.S.-Mexico border in Agua Prieta, with Ana Teresa Fernandez conducting the project in Ciudad Juárez and Maria Teresa Fernandez in Mexicali (bacaz.org). In 2017 M. Jenea 
Sanchez cooperated with ecological artist Lauren Strohacker on the Un-Fragmenting/ Des-Fragmentando project that "confront[ed] the multifaceted ecological effects of the border wall and envision[ed] removing barriers to ensure the survival of a wide diversity of species, including the iconic jaguar" (bacaz.org). Border-related issues she discusses through her works are multifaceted-from ecology and sustainable lifestyles in the borderlands through hybrid identities, religiosity, feminism and the effects of migration. Nevertheless, what is important is the fact that in her works the artist represents those who suffer most in the shadow of the border and includes human stories in those images. It is particularly significant, as the human factor is often either forgotten in discussions on migration or presented through distorted images: people become dehumanized through numbers, figures, and statistics that allow to disregard migrants' lives more easily. The artist's inclusive approach is reflected in the way she represents border journeys in her early documentary production, Historias en la Camioneta (2010).

Historias en la Camioneta (2010) is inspired by M. Jenea Sanchez's childhood in the U.S.-Mexico borderlands and her personal experience of crossing multiple borders. Discussing what motivated her to produce this 20 -minute documentary, the artist reveals:

I grew up on the U.S. Mexico border, and my family and I have used a shuttle service since I was as child to migrate through the landscape to and from larger metropolitan cities such as Los Angeles and Phoenix. When I think about my earliest memories on the shuttle bus, I see my mother immersed in conversations with passengers for hours at a time. ("Historias en la camioneta")

Following in the footsteps of her mother, M. Jenea Sanchez records her and her fellow passengers' conversations on the shuttle bus "to and from Agua Prieta, Sonora Mexico and Phoenix, Arizona" ("Historias en la camioneta"). The journeys across the border and within Mexico and the U.S. respectively become a pretext to undertake a discussion on various border-related issues.

The film begins with a short, almost transient, shot from the waiting room at the bus station in Agua Prieta, Mexico which darkens to show the title-Historias en la camioneta (which can be translated as Stories from the Shuttle Bus), and then the camera closes up on a shuttle bus schedule at the station. The timetable subsequently reappears overwritten on a side window of the van. The driver closes the door and the passengers get seated. All this takes place against the background of voices conversing in Spanish that give way to Mexican music - the scene illustrates aptly the well-known routine of the journey. However, this first scene already suggests it is going to be a special journey. Agua Prieta is one of the "twin cities" alongside the U.S.-Mexico border, with Douglas, AZ to the north. Therefore, the schedule displays cities in the U.S., including the twin city of Agua Prieta - Douglas, AZ or Phoenix, AZ. Such a beginning suggests that the journey will involve a border crossing, which implies an extraordinary character of the trip: crossing any border may be a stressful experience, as it involves specific procedures that control the flow of the border crossers; crossing the border from Mexico to the U.S. can be particularly difficult, due to the additional restrictions and control practices implemented there that make the border less crossable (it needs to be remembered that 
the film was shot in 2010 when the militarization of the border was not developed to such an extent as it is in 2019). Potential obstacles awaiting the passengers of the shuttle are also suggested by physical barriers that separate them from the outside - first, it is the fenced off space of the waiting room at the very beginning of the scene, filmed against the sun, which leaves the space of the station in the dark and makes the fence rods more prominent, as if emphasizing their separating and dividing role. Then it is the shuttle bus itself - the side windows, the windshield, the closing door constitute a physical border between those inside and the outside world. On the one hand, this separation creates a safe and intimate space inside the van, which is important, as it will encourage the subsequent conversations between passengers - they are all enclosed in one place and thus becoming companions for the duration of the trip. On the other hand, those barriers imply further obstacles awaiting them ahead.

This is confirmed in the next scene taking place on the U.S.-Mexico border near the port of entry in Douglas, AZ. It is in this scene that the viewer sees the infamous border fence for the first time - when the van slows down in the line to the port of entry, the fence appears through the side window of the shuttle. It is carefully observed by a little girl who watches the passing road throughout the trip. However, it is only a glimpse and the camera moves back to the inside of the van where the "primer" on the border crossing takes place. It is enough though, to get the idea about the impassability of the border - even if it is still a fence, not a wall, and there is no barbed wire on top of it, it is too tall and too sturdy to go through. Therefore, the border may seem to be permeable on the one hand - one can see through the fence to the other side, but on the other it cannot be crossed freely. Crossing, if permitted, is regulated by numerous procedures and thus becomes a nerve-racking experience in itself. This power of the political line becomes reinforced through the anxious whisper of the child-observer, who, looking through the window notices and whispers "los soldados" (the soldiers). The anxiety aggravates when the driver instructs passengers how to behave when the soldiers enter the van. All this leads to the atmosphere of expectation and tension among the passengers filmed from behind of the bus. Owing to such an angle, the viewer cannot see the faces of the people that would probably reveal more about their feelings, but in this way M. Jenea Sanchez avoids oversimplification in the representation of preparations for the border crossing. The questioning at the border proceeds in a relatively acceptable atmosphere - the questions posed by the officer are very detailed but formal. They are asked in Spanish so that people on the bus do not need translation. Some answers evoke doubts, concerning, for example overstay in the U.S. At the same time some questions also raise confusion, like mispronouncing of names or questions about relations between passengers on a van. Nevertheless, all in all the procedure is quite smooth and apart from the cross-questioning which is stressful in its nature itself, the only implication of tension and anxiety is reflected in the way the scene is filmed. The recording resembles that from a hidden camera, the whole procedure is filmed from the back of the van, but instead of people being questioned or the officer asking those questions, the camera shows the girl-observer, who no longer looks through the window, but instead carefully listens and sometimes responds to the situation around her. This time M. Jenea Sanchez focuses on the face of the girl and it is through her vivid reactions that the viewer gets the idea of the process 
of border crossing. Even though by an analogy to the naïve narrator the girl can be compared to a naïve observer, there are some hints that the girl does understand some implications of the border crossing: there is seriousness in her eyes, she gets anxious when tension or doubts arise about passengers' answers or the officer's questions. It seems it is not the first time she crosses the border and her behavior makes her look mature for her age. This image is particularly powerful, as so far the artist has not shown too many faces of the travelers, let alone focused on them. Filming the reactions of the small girl to the border crossing, M. Jenea Sanchez personalizes the process that is often dehumanized in the media and by the authorities. Consequently, the artist challenges the stereotypical portrayal of the border crossers as the Other or a potential threat to the integrity of the nation-state and instead she replaces it with an image of a small girl, excited and at the same time a bit uneasy about the trip, thus displaying vulnerability of those who travel al otro lado.

The artist defies stereotypes about border crossers also in the following scenes, giving voice to those who are usually silent or silenced, as once the bus crosses the border, the tension is released and the titular stories begin. Altogether there are eleven people relating their stories - seven women and four men. Their accounts are filmed in a specific way - the screen is divided into two parts and on one side the viewer sees the images of the landscape being passed, while to the right the camera focuses on the interlocutor who tells his/her story. The viewer may assume that the story is a developed version of the answer to the question about the reason for travelling and crossing the border - the questions are not recorded and in this way the stories sound more like testimonios than the answers in an interview, which makes it more natural. Moreover, the passing landscapes serve as a backdrop to the stories and contextualize them in space, as the stories are related to the borderlands. As M. Jenea Sanchez admits, "The combination of the passengers' dialogue and changing scenery intimately reveals the interrelationship of personal histories to the particular places passed during the journey" ("Historias en la camioneta."). The stories are interspersed and they vary depending on a person, as the reasons for travel are diverse. Most of the interviewees take this journey because of some family-related purpose which usually involves a visit at the relatives. There are also people who have to solve some legal issues on the other side of the border or those who look for work in the U.S. These conversations remind of a fragment of Elizabeth Bishop's, poem, "The Moose" where "an old conversation/not concerning us, / but recognizable, somewhere,/ back in the bus" (354) takes place, addressing trivial as well as more serious topics. The same is true of the conversations on the shuttle bus when they begin to diverge from personal issues of the passengers' lives, as the stories about the motivation for the journey become a pretext to discuss the question of the U.S.-Mexico border and migration across the line. Then the tone of the stories becomes more serious, as the problems of unemployment, gang violence, or family separations appear in the discussion.

Some passengers refer directly to the issue of migration and migrants' rights, including Woman $3^{1}$ who acknowledges the increasing problems with moving back

1 The names of the interviewees are not given in the film, most probably to make the story more universal. Therefore, for the purpose of identification of subsequent speakers, I introduce the names that allow to determine when each person tells his/her story. 
and forth between the U.S. and Mexico, which prevents her from visiting Mexico more often, as there is always a potential threat she may not be allowed back into the U.S. She emphasizes the aggravation of migration-related problems, focusing on recent separation of families through deportations, particularly of those who "lived their whole lives in the U.S. and are deported" (10:58). Using code-switching she voices her concerns about those deportees who were born in the U.S. and in fact do not know anything about Mexico, often have no relatives there and are suddenly forced to start their lives anew south of the border. She is also the only person who evokes the name of a politician and officer she renders responsible for unlawful, illegal, and racist actions - Joe Arpaio, a former sheriff from Arizona, known for his anti-immigrant attitudes and actions. None of the other passengers ever blame a particular politician, but they usually speak in general terms about border problems. Woman 3, departing from her personal story switches to the political discussion, similarly to the way she oscillates between two languages, Spanish and English, that she uses in her monologue.

The interweaving of personal and political can be also observed in Man 3's account. He undertakes the motif first voiced by Woman 3 and complements her story with an account of his own experience as a migrant who moved to the U.S. as a 12-year-old and has spent most of his life in the U.S. For him, like for the previously mentioned deportees, "coming back" to Mexico resembles more a visit to a foreign country than a nostalgic trip to his homeland. Talking about the U.S., he reveals: "I was raised here, I went to school here, all my friends are here" (14:50) so when he went to Mexico, he did not know his way around, like many other Latinx who have been deported in recent months to Mexico and "find it near impossible to accept [it]... as home" (Duane). His image of the south of the border is that of crime and violence and in his opinion "a lot of bad things go on there" (15:09) because "It's the border, like they say, right?" (15:12). In this way he evokes the issue of the influence of the border on the lives of borderlanders and also those living further away in terms of distance, but still in the shadow of the border both in the U.S. and in Mexico, as its power is farreaching and often destructive.

It has to be noted that after those two stories, to balance their negative undertone, M. Jenea Sanchez interviews also other passengers who prefer Mexico over the U.S. Some, like the last person interviewed-Woman 7-come up with yet another alternative to the divisiveness of the border. The last interlocutor travels back and forth between Agua Prieta and Arizona, as her husband is waiting for his residency in the U.S. to be approved. However, she admits, that once the legal issues are solved, they are planning to live literally between two states. She wants her children to attend private school in Mexico and she will continue working in Arizona, thus becoming a nomad travelling between those two places. It is by no means an accident that the artist concludes the storytelling and the film with that account, as it balances arguments for and against migration. At the end of the film M. Jenea Sanchez provides an alternative that connects both sides of the border, and owing to that, the border's presupposed role to divide two individual nation-states is challenged to transform this space into a "contact zone" (Pratt in Benito and Manzanas 4) or "crossroads" (Anzaldúa 12) that allow for a dialogue between two sides of the line as well. Consequently, those who choose such an alternative formulate nomadic identities, which implies carrying their 
homes on their back like Anzaldúa's turtle - the image she evokes in Borderlands/La Frontera to describe her fluid identity (43). It needs to be remembered, though, it is not a new construct, as transborder identities and culture have functioned for a long time in the U.S.-Mexico borderlands, when the border was still more passable - the times M. Jenea Sanchez remembers from her childhood memories of journeys on the shuttle bus.

Viktoria Byczkiewicz, quoting Bill Nichols, maintains that "[d]ocumentaries may be informative, yet they must be understood more precisely as argumentative, with the goal of furthering the filmmaker's favored worldview" (2) and it can be argued that Historias en la Camioneta is not only a collection of personal stories of border crossers and a celebration of M. Jenea Sanchez's childhood memories, but it also contributes to the discussion on the migration from Mexico - in this way personal becomes political as well. Many of the arguments provided by the artist's fellow travelers echo the problems of migration researchers enumerate in their analyses. Paul Ganster synthesizes the most salient U.S.-Mexico migration-related issues of the twentieth and twenty-first centuries in The U.S.-Mexican Border Today: Conflict and Cooperation in Historical Perspective. In the chapter devoted to modern migration Ganster argues that migration, as "one of the most enduring and sensitive border issues for Mexico and the United States" (215) became a problem in the twentieth century (215). He maintains that "[f]rom 1848 until the end of the nineteenth century, the border was not patrolled, and migration across it concerned few people" (215). Moreover, "[e]arly U.S. immigration legislation (in 1917 and 1924) generally made exceptions for Mexican migrants" (215). Ganster's arguments are also reiterated in Greg Grandin's examination of the evolution of militarization of la frontera and he ties it to the involvement of the U.S. in international interventions. Francisco Cantú summarizes Grandin's conclusions and states that the process commenced at the beginning of the twentieth century_-"[a]s America thrust itself into the wider world, it simultaneously began a process of shoring up its domestic borders" (75). Grandin's examination of walling off the borders is aptly combined with the history of racism in the U.S. and how racial tensions have been channeled and diverted from domestic space to the international arena through the abovementioned American interventions all over the world (Cantú 76). ${ }^{2}$ Ganster, in turn, conducts the analysis of domestic factors that have

2 Cantú concludes: "Part of Grandin's achievement in "The End of the Myth" is to situate today's calls to fortify our borders in relation to the centuries of racial animus that preceded them. Donald Trump can be distinguished from his predecessors, Grandin argues, because of his willingness to meet conservative and nativist demands at their logical end point-by closing off instead of moving out. By contrast, his predecessors over the past four decades each found ways of channeling aggression outward by identifying new frontiers and promising boundlessness in a shrinking world. Reagan pursued anti-Communist wars in Central America by declaring it "our southern frontier"; George H. W. Bush saw the crumbling of the Berlin Wall and imagined "new markets for American products," proclaiming that "in the frontiers ahead, there are no borders"; Clinton declared, as he signed NAFTA, that "this new global economy is our new frontier"; and George W. Bush launched a global war on terror with the promise to "extend the frontiers of freedom." After America's military failure in Iraq and its economic failure in the Great Recession, the nation's first African-American President arrived in office at the precise moment when hatred was coming home from the fringes" (76). 
led to the perception of migration from Mexico as a tenuous issue and places them in the context of Mexican-American relations in the twentieth and twenty-first centuries.

Ganster attributes the origins of the "tensions caused by the migration issue, as we now think of" (215) to the Bracero Program and subsequent "emergence of a network throughout Mexico, at the border and in the United States that both stimulated and facilitated migration for seasonal or permanent employment in the United States" (215) and which continued even after the official completion of the program in an unofficial way, as Mexican workers have been in constant demand for the development of the American economy. However, as Ganster argues, with time and with legislative changes that transformed Mexican migrants into illegal immigrants, permanent migration replaced seasonal migration and it became "increasingly characterized by the movement of families rather than individual males" (215). At the same time, the shift in the debate on immigration took place "from a traditional focus on quotas for legal immigrants to concerns about illegal, or unauthorized, immigrants" (216), which led to the introduction of subsequent discriminatory policies and acts of law, including, for example, Operation Hold the Line or Operation Gatekeeper (Ganster 219). In spite of those practices, the flow of people from Mexico continued, since, according to Ganster, it is a popular misconception that migration was based solely on the poverty in Mexico, particularly in the southern regions. He claims that it in fact "correlates much more strongly with U.S. employment needs than with Mexican unemployment" (216). Moreover, its "principal benefit to employers of migrant labor was not its low costs but its flexibility" (217). Looking from the perspective of those who migrated to the U.S. "the simple push-and-pull factors of wage differentials" (Ganster 217) were far less important than "global issues of market consolidation (including North American integration), the process of learning that accrues to migrants... and the network created by migration" (217). In other words, as Ganster argues, "[m]igrants sought not income but investment capital and insurance against risk in their communities of origin" (217). It also has to be noted that Mexican migrants have assimilated much faster into the American society than other groups through different procedures, such as, for example, mixed marriages (Ganster 216-217).

In spite of all these factors, the fear of the Mexican immigrant as the Other, posing a threat to the aforementioned apparent integrity of the nation-state has continued and fueled subsequent legal acts (or lack of legislature as Jeffrey Toobin suggests in "American Limbo") and procedures, including Operation Wetback, Operation Gatekeeper or Operation Hold the Line aimed at stopping immigration from across the U.S.-Mexico border. Those operations pushed those who wanted to cross the border to more dangerous regions of the deserts and mountains, turning border crossing into a lethal undertaking. In addition, as Ganster maintains, those policies have been counterproductive and, instead of driving away migrants, "increased the numbers of permanent undocumented residents, converting a circular movement into a unidirectional flow" (218), as "stepped-up enforcement discouraged migrants from returning to Mexico and encouraged them to remain permanently in the United States" (219). Consequently, as it is often true in the case of the borderlands, decisions made centrally, have not addressed "the realities of the border region with Mexico" (Ganster 220) and disregarded the complex character of migration across the U.S.- 
Mexico border (this analysis focuses on migrants from Mexico solely, due to its scope and does not examine recent immigration from Central America in general and the Northern Triangle in particular that would require another analysis). Thus it seems that migration from Mexico will remain an unsolved issue and the focus of the twentyfirst century debates in the U.S. and in Mexico, taken up by politicians and used to their advantage with disregard to those who suffer in the process. M. Jenea Sanchez's stories from the shuttle bus constitute a contribution to the debate on the U.S.-Mexico border which in an apparently informal way transform personal accounts into political arguments, thus challenging the stereotypical portrayal of la frontera and those who cross the border in both directions.

\section{Works Cited}

Anzaldúa, Gloria. Borderlands/La Frontera: The New Mestiza. San Francisco: Aunt Lute Books, 1999. Print.

Benito, Jesús, and Ana M. Manzanas. "Border(lands) and Border Writing: Introductory Essay." Literature and Ethnicity in the Cultural Borderlands. Ed. Jesús Benito and Ana M. Manzanas. Amsterdam and New York: Rodopi, 2002. 1-21. Print.

Bishop, Elizabeth. "The Moose." The Wadsworth Anthology of Poetry. Ed. Jay Parini. Belmont: Thomson Wadsworth, 2006. 354. Print.

Byczkiewicz, Viktoria. Blaming, Shaming, and Framing the Immigrant as Other in U.S.-Mexico Borderlands Cinema: A Discursive and Psychological Analysis. Los Angeles: Trébol Press, 2013. Print.

Cantú, Francisco. "Boundary Conditions: What happens when the American frontier becomes a wall?" The New Yorker, 11 March 2019: 73-77. Print.

Duane, Daniel. "City of Exiles." The California Sunday Magazine. 30 May 2018. Accessed 15 Apr 2019. Web.

Ganster, Paul. The U.S.-Mexican Border Today: Conflict and Cooperation in Historical Perspective. Lanham: Rowman and Littlefield, 2016. Print.

Grandin, Greg. The End of the Myth: From the Frontier to the Border Wall in the Mind of America. New York: Metropolitan Books, Henry Holt and Company, 2019. Print.

Pratt, Mary Louise. Imperial Eyes: Travel Writing and Transculturaltion. London: Routledge, 1992. Print.

Sanchez Jenea, M. Historias en la camioneta. YouTube, uploaded by M. Jenea Sanchez, 12 October 2011, www.youtube.com/watch?v=ZGOSBLhqwOM.

_. "Historias en la camioneta." phoenixtransect.org. Web. Accessed 10 Jan 2019.

—. mjeneasanchez.com. Web. Accessed 10 Jan 2019.

Toobin, Jeffrey. "American Limbo: While Politicians Block Reform, What Is Happening to Immigrant Families?” The New Yorker, 27 July 2015. 30-35. Print. 
